OPEN ACCESS

Edited by:

Lee Samuel Finn

Pennsylvania State University, USA

Reviewed by:

Elizabeth Blaber,

National Aeronautics and Space

Administration, USA

Mauro Maccarrone,

Università Campus Bio-Medico, Italy

*Correspondence:

Gian C. Demontis

giancarlo.demontis@farm.unipi.it

Specialty section: This article was submitted to

Cosmology

a section of the journa

Frontiers in Astronomy and Space

Sciences

Received: 31 March 2016 Accepted: 05 April 2017

Published: 25 April 2017

Citation:

Andreazzoli M, Angeloni D, Broccoli V and Demontis GC (2017) Microgravity,

Stem Cells, and Embryonic

Development: Challenges and

Opportunities for 3D Tissue

Generation.

Front. Astron. Space Sci. 4:2

doi: 10.3389/fspas.2017.00002

\section{Microgravity, Stem Cells, and Embryonic Development: Challenges and Opportunities for 3D Tissue Generation}

\author{
Massimiliano Andreazzoli ${ }^{1}$, Debora Angeloni ${ }^{2}$, Vania Broccoli ${ }^{3,4}$ and Gian C. Demontis ${ }^{5 *}$ \\ ${ }^{1}$ Department of Biology, University of Pisa, Pisa, Italy, ${ }^{2}$ Institute of Life Sciences, Scuola Superiore Sant'Anna, Pisa, Italy, \\ ${ }^{3}$ National Research Council, Institute of Neuroscience, Milan, Italy, ${ }^{4}$ Stem Cells and Neurogenesis Unit, Division of \\ Neuroscience, San Raffaele Scientific Institute, Milan, Italy, ${ }^{5}$ Department of Pharmacy and Centro D’Ateneo "E. Piaggio", \\ University of Pisa, Pisa, Italy
}

Space is a challenging environment for the human body, due to the combined effects of reduced gravity (microgravity) and cosmic radiation. Known effects of microgravity range from the blood redistribution that affects the cardiovascular system and the eye to muscle wasting, bone loss, anemia, and immune depression. About cosmic radiation, the shielding provided by the spaceship hull is far less efficient than that afforded at ground level by the combined effects of the Earth atmosphere and magnetic field. The eye and its nervous layer (the retina) are affected by both microgravity and heavy ions exposure. Considering the importance of sight for long-term manned flights, visual research aimed at devising measures to protect the eye from environmental conditions of the outer space represents a special challenge to meet. In this review we focus on the impact of microgravity on embryonic development, discussing the roles of mechanical forces in the context of the neutral buoyancy the embryo experiences in the womb. At variance with its adverse effects on the adult human body, simulated microgravity may provide a unique tool for understanding the biomechanical events involved in the development and assembly in vitro of three-dimensional (3D) ocular tissues. Prospective benefits are the development of novel safety measures to protect the human eye from cosmic radiation in microgravity during long-term manned spaceflights in the outer space, as well as the generation of human 3D-retinas with its supporting structures to develop innovative and effective therapeutic options for degenerative eye diseases.

Keywords: retinal development, iPS cells, 3D tissue models, retinal diseases, biomechanics, buoyancy

\section{THE HUMAN BODY IN SPACE FACES THE CHALLENGES POSED BY MICROGRAVITY AND COSMIC RADIATION}

Microgravity and cosmic radiation pose significant health hazards to astronauts during long-duration spaceflights and are of special concern for the prospective exploration of the outer space.

Although the word microgravity conveys the notion of a dramatically reduced force of gravity, at the low Earth orbit (LEO, about $370 \mathrm{~km}$ of altitude) gravity is nearly $89 \%$ of its ground level. However, an apparent centrifugal force related to the speed of the orbiting spaceship (about 
$28,000 \mathrm{~km} / \mathrm{h}$ ) balances gravity. Therefore, microgravity indicates the condition of weightlessness experienced by astronauts inside the spaceship.

Microgravity adverse effects on the human body range from endothelial cells (Versari et al., 2013) and blood distribution to endocrine and reflex mechanisms controlling body water homeostasis and blood pressure (Taibbi et al., 2013; Nelson et al., 2014). Long-duration spaceflights also cause muscle wasting (Gopalakrishnan et al., 2010), severe bone loss (Keyak et al., 2009), immune depression (Cogoli et al., 1984; Cogoli, 1993; Battista et al., 2012; Gasperi et al., 2014), and ophthalmic problems (Nelson et al., 2014).

Astronauts also face the hazard posed by the cosmic radiation, as they lack the protection afforded by the combined effects of the Earth atmosphere and magnetic field. Astronauts are exposed to high energy heavy ions of the cosmic radiation (Pinsky et al., 1975; Casolino et al., 2003b), as suggested by properties and relative abundance of particles inside space vehicles (Benton et al., 1975; Pinsky et al., 1975; Casolino et al., 2003a,b; Di Fino et al., 2011).

\section{MICROGRAVITY, ADULT STEM CELLS, AND TISSUE RENEWAL}

Studies aimed at evaluating the link between microgravity and impaired tissue renewal by adult stem cells generated conflicting results, with methodological differences between simulated microgravity (SMG) and real microgravity aboard spacecrafts representing a confounding factor. We will now summarize the main features of devices used to generate SMG, such as clinostat, random positioning machine (RPM), rotating wall vessel (RWV; for a review see Herranz et al., 2013).

In the clinostat, the gravity force still acts on cells but its direction changes rhythmically, due to the rotation around a single axis oriented $90^{\circ}$ to the gravity vector (Dedolph and Dipert, 1971), thus averaging the gravity vector to zero. The critical point is the minimal presentation time, the minimum amount of time the gravity vector has to keep a steady orientation to generate a response (Brown et al., 1976). In plants, this time ranges from $<20$ to over $200 \mathrm{~s}$ but is 2 or more order of magnitude shorter in mammalian cells, which therefore require a fast rotating clinostat (Cogoli, 1992). The RPM nullifies the average gravity vector, although over a limited space, by rotating randomly and at variable speeds on multiple axes. Therefore, RPM is suitable for small samples, and rather than a true microgravity cells will experience continuous changes of the gravity vector that in plants may approximate real microgravity (Hoson et al., 1997).

On the other hand, the RWV incubator keeps cells in suspension by causing the fluid to move around them (Hammond and Hammond, 2001). The device needs a fine tuning to strike a balance between multiple factors, such as the revolving speed of the RWV, the radius of cells/aggregates and the difference in densities between cells and fluid. Interestingly, the streaming fluid generates mechanical forces (i.e., shear stress), but also increases oxygen and nutrients available to cells cultured in the RWV, by relieving them from the diffusion-limit that holds in static cultures (Kwon et al., 2008). Thus, the RWV may favor the growth of larger tissue aggregates (Lelkes et al., 1998; Barzegari and Saei, 2012) compared to static culture conditions (Mueller-Klieser et al., 1986; Sutherland et al., 1986). RWV culturing may prove advantageous for tissue with high metabolic rates, such as the retina (Ye et al., 2010), which must support the high costs of ion transport in darkness (Demontis et al., 1995) and phototransduction in light (Demontis et al., 1997). Improved culturing of stem cells-derived photoreceptors may also enhance their light responsiveness (Demontis et al., 2012; Zhong et al., 2014).

Data indicate differences between real and SMG on the rate of proliferation, stemness, cell cycle kinetics, and differentiative potentials of cell types as diverse as hematopoietic stem cells (CD34+), osteoblasts, and multilineage (mesenchymal) stem cells. For instance, the proliferation of $\mathrm{CD} 34+$ was reduced during LEO flights compared to ground controls, with the differentiation toward the macrophage at the expense of human myeloid and erythroid pre-cursors (Davis et al., 1996). On the other hand, despite similarly reduced proliferation during a comparable time span, SMG (RWV) was reported to steer human $\mathrm{CD} 34+$ cells toward the myeloid fate, an effect associated with slowed S-phase of the cell cycle (Plett et al., 2004). At variance with the above findings, CD34+ cells increased their proliferation rate when cultured in RWV in the presence of VEGF, and differentiated into endothelial precursors (Chiu et al., 2005). Similar conflicting results were generated using multilineages bone marrow mesenchymal stem cells (MSCs). Human MSCs cultured in SMG (clinostat) increased proliferation and differentiate toward a chondrogenic phenotype upon transplantation in cartilagedeficient rats (Yuge et al., 2006). In contrast, rat MSCs in SMG (clinostat) reduce their proliferation and ability to differentiate toward a chondrogenic fate (Yan et al., 2015). In mouse, bone resorption in microgravity associates with the downregulated expression of genes involved in early mesenchymal and erythropoietic differentiation, and maintained stem cells markers expression (Blaber et al., 2014). When cultured in 1 g, cells previously exposed to microgravity display an increased mesenchymal and hematopoietic differentiation, suggesting that microgravity causes an accumulation of undifferentiated precursors (Blaber et al., 2014). A role for the autophagic control of osteoclastogenesis in response to microgravity has been proposed for mouse bone (Sambandam et al., 2014). A recent review by Ulbrich et al. (2014) details the impact of simulated and real microgravity on bone and mesenchymal cells and their osteogenic potential.

It is important to note that differences between either real or SMG may not be apparent at the morphological level. For instance, thyroid cancer cells formed spheroids of similar morphology (although slightly dissimilar in size) under both real (Pietsch et al., 2013) and SMG (Grimm et al., 2002; Ma et al., 2014; Warnke et al., 2014). However, at the level of gene or protein dosage, it becomes evident that at least in some systems space flight and ground simulators exert different effects (Hammond et al., 1999). These differences may be relevant for complex 
and sophisticated biological systems, such as stem cells in their niche.

Last, spaceflight and clinostat did not change the secretion of growth factors such as EGF and VEGF, at variance with RPM (Warnke et al., 2014). Therefore, different simulators may cause different effects and introduce confounding effects in the analysis of the impact of real microgravity on the proliferation and differentiation of adult stem cells toward specific cell fate.

Flight-associated stress is an additional confounding factor that may contribute to suppressing lymphoid tissue response to immunological challenging (Fitzgerald et al., 2009) and the immune depression observed in astronauts (Cogoli et al., 1984; Cogoli, 1993) also through apoptotic death (Battista et al., 2012).

\section{MICROGRAVITY, EMBRYONIC STEM CELLS, AND DEVELOPMENT}

In addition to adult stem cells, microgravity may also affect embryonic development.

Spaceflight preserves the stemness of mouse embryonic stem (ES) cells-derived progenitors and inhibits the expression of markers of terminal differentiation for tissues derived from the three primary germ layers (Blaber et al., 2015). However, differences in the proliferation rate of mouse embryonic stem (ES) cells cultured in SMG were shown to be transient, subsiding after the 2nd day, with no difference in cell cycle kinetics compared to $1 \mathrm{~g}$ controls (Wang et al., 2011). The reduced implantation efficiency of either zygotes or blastocysts generated in SMG (Wakayama et al., 2009) may also indicate an effect on ES cells that impacts on early developmental stages of mammalian embryos. However, the impaired viability of RWVcultured embryos may result from the shear stress-triggered (Xie et al., 2006) increase in NO free radicals (Cao et al., 2007), and is therefore unclear whether the adverse effects on implantation are caused by microgravity rather than by a side effect of the culturing system.

Studies also addressed the effects of microgravity on the early stages of embryonic development of fish, amphibian, and birds. In amphibia, the most consistent changes reported at early developmental stages for oocytes developing in microgravity are the abnormal division plane of the zygote and an increased thickness of the roof of the blastocoel cavity at the gastrulae stage (Souza et al., 1995). Additional examples of adverse effects of microgravity on early embryonic development are the high mortality observed in chicken eggs raised in microgravity from oviposition time, due to the yolk failure to float in the albumen, thus preventing the chorioallantoic membranes from establishing a functional contact with the shell (Suda, 1998; Pearson, 2004).

At the hatching tadpole stage, amphibian embryos raised in SMG had enlarged head and eyes (Neff et al., 1993), with opposite effects observed under increased gravity. These phenotypes may relate to the effects of microgravity on the cytoskeleton (summarized in Crawford-Young, 2006). A further, not mutually exclusive, possibility is that the observed phenotypes could result from an altered proliferation of the anterior neural system. However, the observation that adult frogs raised in microgravity are indistinguishable from those raised in $1 \mathrm{~g}$ might indicate that, similarly to mouse ES cells, the effects of microgravity are transient (Neff et al., 1993). In general agreement with this notion, abnormalities of cytoplasm movements, and cell adhesion in response to microgravity were found temporary and, in general, reversible (Gualandris-Parisot et al., 2002). Furthermore, there is evidence that in embryonic tissues the effects of microgravity on gene expression may depend on the developmental time, with changes in $\beta$-actin expression in zebrafish embryos raised in microgravity peaking in the time window spanning $24-72 \mathrm{~h}$ post-fertilization (Shimada et al., 2005).

These data may indicate that, similar to mouse ES cells, fish and amphibians embryos either adapt to microgravity during early development, or their susceptivity to microgravity is restricted over an early and short time span, making later developmental stages resilient to long-lasting changes in the force of gravity. The similarity of the embryonic responses to microgravity is somewhat surprising, considering that amphibia and fish develop in water, protected from the multiple mechanical forces acting upon mammalian embryos. However, analysis of the embryonic development in mammals reveals some surprising analogies with the conditions occurring in fish and amphibia.

\section{GRAVITY, BUOYANCY, AND EARLY EMBRYONIC DEVELOPMENT}

As shown in Figure 1, when the zygote reaches the uterus, about 5-6 days after fertilization, a characteristic structural rearrangement converts a compact mass of cells to a hollow sphere filled with fluid, the blastocyst. At this stage, at one pole of the blastocyst lies an inner mass of pluripotent stem (PS) cells, which will generate all the embryo tissues and extraembryonic membranes except for the chorion, which will give rise to the placenta. After the blastocyst implants in the uterine wall, the inner cell mass will organize into the hypoblast and the epiblast epithelial layers, the latter lining an additional cavity that will fill up with the amniotic fluid (AF).

Therefore, the complex biomechanical rearrangement of the embryo from flat germ layers (ectoderm, mesoderm, and endoderm) into three-dimensional (3D) organs and tissues do occur while immersed in the AF. As highlighted in Figure 1, every immersed body will experience a gravity-opposing force or buoyant force. Whether this upward-directed force prevents the body from sinking will depend on the difference between the densities of the liquid and of that of the immersed body, the well-known Archimedes' principle or physical law of buoyancy. AF composition is similar to adult blood plasma, being mostly water with salts and proteins, and its relative density is close to 1 (Underwood et al., 2005). Intriguingly, relative densities of embryo tissues are lower than in the adult, with the newborn value close to 1.00 , lower than the adult value of 1.07 (Weststrate and Deurenberg, 1989). Therefore, during a time window going from about 10 days post fertilization 


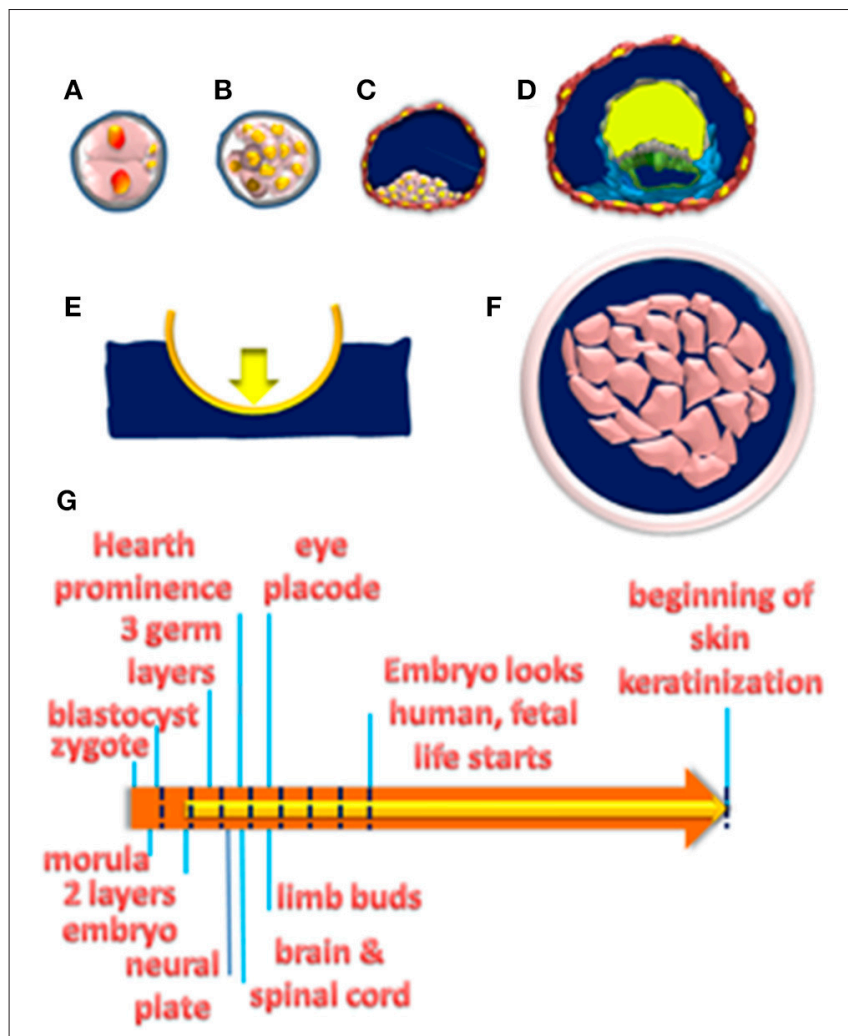

FIGURE 1 | (A-D) Schematic representation of the main embryonic developmental stages. Two-cell zygote (A); compact cell mass at morula (B); blastocyst stages (C); with trophoblast cells (brown) encircling a cavity filled by fluid (blue) where the inner cell mass (pink) sits at one pole. In (A,B) cells are encased by the zona pellucida (gray). Zygote development up to the blastocyst stage does occur before implantation. (D) Formation of hypoblast (gray) and epiblast (green) layers after implantation. The initial amniotic cavity is delimited by epiblast cells and filled with fluid (blue). The cavity above the hypoblast is the yolk sac, which fills up with the yolk (yellow) and regresses at later developmental stages. (E) A boat in the fluid will sink or float, depending on the difference between the force of gravity (downward pointing yellow arrow) and the buoyant force (upward pointing blue arrow). The rigid hull absorbs the opposing forces and people inside the floating boat do experience gravity. (F) A cell mass (pink) immersed in a fluid (blue) that has access to the interstitial fluid between cells. (G) The orange arrow plots the timeline of organ morphogenesis between implantation and the 20th week when skin keratinization starts. The yellow arrow plots the time of amniotic fluid formation. Blue dashed lines plot 1-week intervals till the 8th week when fetal life starts.

up to the 20th week the increase in AF volume matches that of the embryo (Underwood et al., 2005). Therefore, embryonic development takes place in a condition of neutral buoyancy, i.e., the buoyant force just matches and opposes gravity, due to the similar densities of the embryo and the AF he is immersed in (Sekulic et al., 2005). This condition of neutral buoyancy is likely to progressively vanish after the 20th week when the AF volume decreases and the increase in the size of the fetus reduce its buoyancy (Sekulic et al., 2005).

Importantly, in case the immersed body has rigid walls that absorb the buoyant force, objects inside do not experience a condition of neutral buoyancy, i.e., they still feel the full

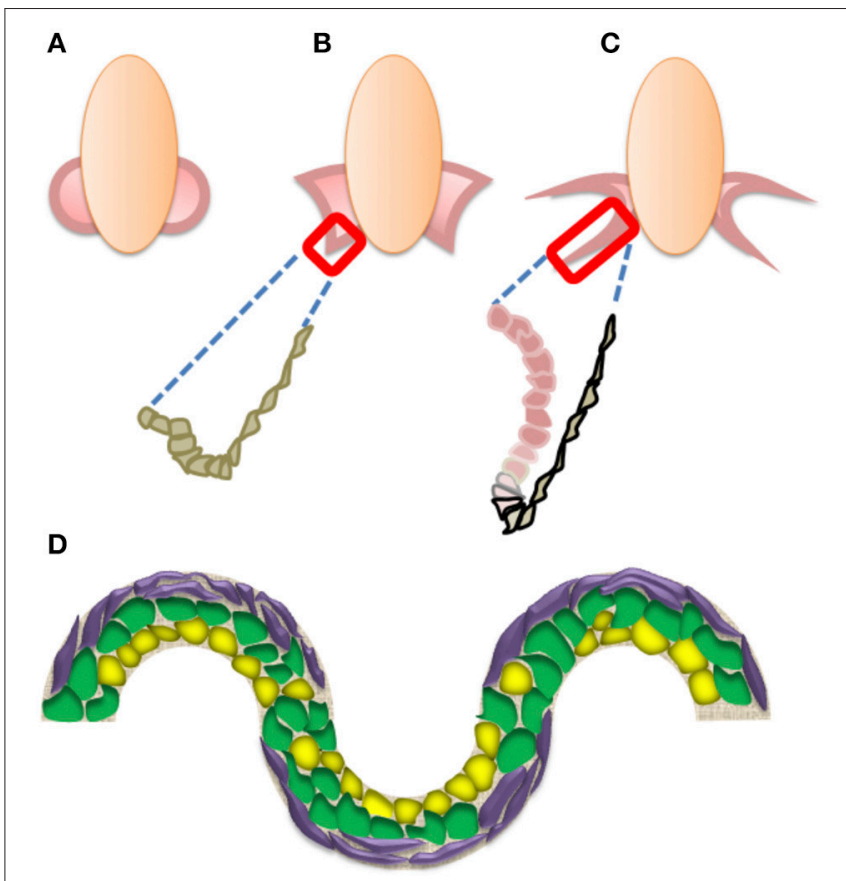

FIGURE 2 | (A-C) Schematic representation of the main steps in retinal formation. Optic vesicles form by evagination (A), and then flatten upon the formation of hinges, where cells undergo apical constriction (B). The next step (C) is the invagination starting at the hinge region (gray), driven by the proliferation of neural retina pre-cursors (pink) illustrated in the box in (B, C). Pigment epithelium-fated cells are black-lined. (D) Schematic drawing of the effects of substrate shapes on stem cell differentiation. Multilineage cells (green) may take either an adipogenic (yellow) or osteogenic (purple) fate at concave or convex shapes, respectively.

force of gravity, as in the case of people sitting in a floating boat. On the other hand, if the immersed body lacks a hard shell then the buoyant force will be transmitted to the fluid inside and is expected to relieve tissues from the influence of gravity. Interestingly, in the human embryo skin keratinization starts at about the 20th week (Underwood et al., 2005) so that the extracellular fluid in the interstitial spaces between cells is in contact with the AF. Intriguingly, the development of most $3 \mathrm{D}$ structures in the developing embryo takes place in the time window between 1 and 20 weeks, when AF is in contact with the extracellular spaces and may generate a buoyant force to relieve cells from gravity. Note that for the buoyant force to effectively counteract gravity, subcellular compartments should have the same densities, a notion consistent with data from magnetic levitation experiments (Valles and Guevorkian, 2002).

\section{MECHANICAL FORCES AND FATE ASSIGNMENT}

Insights into the possible role of microgravity during organogenesis may come from the analysis of the biomechanics of 3D tissue generation in vitro. Figure 2 illustrates the development of the retina as assessed in vitro (Sasai et al., 
2012), from either mouse ES (Eiraku et al., 2011), or human iPS cells (Nakano et al., 2012). The three main developmental steps involved in retina formation involve the generation of the dome-shaped optic vesicle, which will flatten before invaginating toward the innermost part of the vesicle. The critical event in the invagination is the apical constriction of the cells of the epithelial layer at a special transition zone, to form a mechanical hinge between the pigmented epithelium- and retinal-fated epithelial layers. After the invagination, the growth of the retinal-fated layer is sensitive to inhibitors of the mitotic fuse indicating a role for the pressure exerted by the expansion of the proliferating epithelium, thus highlighting the importance of cell proliferation for 3D tissue development.

On the other hand, the biomechanical events involved in the folding and bending of epithelial sheets, with the generation of concave and convex surfaces, should also consider the roles of mechanical forces as morphogens that affect cell fate. Multilineage MSCs cultured in medium containing differentiation factors favoring both adipose as well as bone tissue development could be coaxed toward either an adipogenic or an osteogenic fate using sinusoidally-shaped adhesive surfaces. Specifically, they are mostly fated to adipose cells at the concave edges, while taking an osteogenic fate at the convex edges (Ruiz and Chen, 2008). Intriguingly, the stronger mechanical forces exerted at the convex than at the concave edges are critical for steering MSCs toward the osteogenic fate (Ruiz and Chen, 2008). Substrate stiffness is also important in steering MSCs fate (Engler et al., 2006), and recent evidence indicates its involvement with $3 \mathrm{D}$ topography in controlling the stemness of ES cells (Lü et al., 2014). These data suggest that tensile gradients may operate as mechanical morphogens.

The notion of mechanical morphogens may provide a different perspective on the biomechanical events taking place in $3 \mathrm{D}$ tissue development. The conceptual framework based on quantitative models (Keller and Shook, 2011; Fletcher et al., 2014) of the complex spatial and temporal dynamics (Eiraku et al., 2012) underlying epithelial sheets folding in 3D structures during embryonic development focuses on wedges formation in response to chemical morphogens gradients. In turn, it is conceivable that wedges formation prompted by chemical morphogens may trigger forces that operate as mechanical morphogens, which will act synergically with their chemical triggers. This positive feedback may force fate assignments by letting cells overcome a barrier in their developmental landscape. According to this view, during the early stages of embryonic development of $3 \mathrm{D}$ body structures, the buoyant force may increase the overall efficiency of the process by relieving the perturbing effects of gravity on mechanical morphogens.

\section{REFERENCES}

Barzegari, A., and Saei, A. A. (2012). An update to space biomedical research: tissue engineering in microgravity bioreactors. Bioimpacts 2, 23-32. doi: $10.5681 /$ bi.2012.003

\section{D-TISSUE GENERATION IN MICROGRAVITY: IMPACT ON OUTER SPACE EXPLORATION AND QUALITY OF LIFE OF AN AGING POPULATION}

If microgravity were to play a role in embryonic development beyond the unleashing of the full potential of mechanical morphogens, it could be the delaying of stem cells differentiation while maintaining them in a proliferative state. In the newt, the retina grows through adult life, and both spaceflight and SMG promote retinal regeneration in response to damage via an increased cell proliferation in the early stages of regeneration during spaceflight (Grigoryan et al., 1998, 2002). The expected consequence of an expanded progenitors pool would be the increased size of developing tissues. Indeed, in a clinical condition known as microcephaly, a genetic defect leading to an earlier than usual differentiation of radial glia progenitors reduces the generation of neurons required to populate and build up the cortex (Lancaster et al., 2013), ending up with reduced cortical size. According to this notion, exploiting inducible PS cells (iPS) technology (Takahashi et al., 2007; Nakagawa et al., 2008), it would be possible to generate larger human 3D retinas in microgravity. Human retinas generated in microgravity might be used to address the roles of microgravity and cosmic radiation in eye damage associated with prolonged manned space flights (Nelson et al., 2014).

Understanding the possible role of microgravity in 3D tissue development may foster either regenerative medicine approaches or the development of improved assays to evaluate safety and efficacy of new therapeutic agents for degenerative diseases. Novel approaches may be of special importance for retinal degenerations, such as retinitis pigmentosa and age-related macular degenerations (Caras et al., 2014; Zarbin, 2016), which represent a significant cause of blindness and presently lack proven effective therapeutic options (Zarbin et al., 2014).

\section{AUTHOR CONTRIBUTIONS}

MA, DA, VB, and GD conceived, wrote, and critically revised the paper and approved its final version. Authors agree to be accountable for all aspects of the work in ensuring that questions related to the accuracy or integrity of any part of the work are appropriately investigated and resolved.

\section{ACKNOWLEDGMENTS}

This paper relies on the work on regenerative approaches in retinal degenerations, which is supported by a grant from Fondazione Roma to VB, DA, MA, and GD (Retinite pigmentosa (RP) call for proposal 2013-Project RP-2013-00000013).

Battista, N., Meloni, M. A., Bari, M., Mastrangelo, N., Galleri, G., Rapino, C., et al. (2012). 5-Lipoxygenase-dependent apoptosis of human lymphocytes in the International Space Station: data from the ROALD experiment. FASEB J. 26, 1791-1798. doi: 10.1096/fj.11199406 
Benton, E. V., Henke, R. P., and Bailey, J. V. (1975). Heavy cosmic-ray exposure of Apollo astronauts. Science 187, 263-265. doi: 10.1126/science.1111101

Blaber, E. A., Dvorochkin, N., Torres, M. L., Yousuf, R., Burns, B. P., Globus, R. K., et al. (2014). Mechanical unloading of bone in microgravity reduces mesenchymal and hematopoietic stem cell-mediated tissue regeneration. Stem Cell Res. 13, 181-201. doi: 10.1016/j.scr.2014.05.005

Blaber, E. A., Finkelstein, H., Dvorochkin, N., Sato, K. Y., Yousuf, R., Burns, B. P., et al. (2015). Microgravity reduces the differentiation and regenerative potential of embryonic stem cells. Stem Cells Dev. 24, 2605-2621. doi: $10.1089 / \mathrm{scd} .2015 .0218$

Brown, A. H., Dahl, A. O., and Chapman, D. K. (1976). Limitation on the use of the horizontal clinostat as a gravity compensator. Plant Physiol. 58, 127-130. doi: 10.1104/pp.58.2.127

Cao, Y. J., Fan, X. J., Shen, Z., Ma, B. H., and Duan, E. K. (2007). Nitric oxide affects preimplantation embryonic development in a rotating wall vessel bioreactor simulating microgravity. Cell Biol. Int. 31, 24-29. doi: 10.1016/j.cellbi.2006.09.003

Caras, I. W., Littman, N., and Abo, A. (2014). Proceedings: debilitating eye diseases. Stem Cells Transl. Med. 3, 1393-1397. doi: 10.5966/sctm.2014-0221

Casolino, M., Bidoli, V., De Grandis, E., De Pascale, M. P., Furano, G., Morselli, A., et al. (2003a). Study of the radiation environment on MIR space station with SILEYE-2 experiment. Adv. Space Res. 31, 135-140. doi: 10.1016/S0273-1177(02)00880-3

Casolino, M., Bidoli, V., Morselli, A., Narici, L., De Pascale, M. P., Picozza, P., et al. (2003b). Space travel: dual origins of light flashes seen in space. Nature 422:680. doi: $10.1038 / 422680$ a

Chiu, B., Wan, J. Z., Abley, D., and Akabutu, J. (2005). Induction of vascular endothelial phenotype and cellular proliferation from human cord blood stem cells cultured in simulated microgravity. Acta Astronaut. 56, 918-922. doi: 10.1016/j.actaastro.2005.01.018

Cogoli, A. (1993). Space flight and the immune system. Vaccine 11, 496-503. doi: 10.1016/0264-410X(93)90217-L

Cogoli, A., Tschopp, A., and Fuchs-Bislin, P. (1984). Cell sensitivity to gravity. Science 225, 228-230. doi: 10.1126/science.6729481

Cogoli, M. (1992). The fast rotating clinostat: a history of its use in gravitational biology and a comparison of ground-based and flight experiment results. ASGSB Bull. 5, 59-67.

Crawford-Young, S. J. (2006). Effects of microgravity on cell cytoskeleton and embryogenesis. Int. J. Dev. Biol. 50, 183-191. doi: 10.1387/ijdb.052077sc

Davis, T. A., Wiesmann, W., Kidwell, W., Cannon, T., Kerns, L., Serke, C., et al. (1996). Effect of spaceflight on human stem cell hematopoiesis: suppression of erythropoiesis and myelopoiesis. J. Leukoc. Biol. 60, 69-76.

Dedolph, R. R., and Dipert, M. H. (1971). The physical basis of gravity stimulus nullification by clinostat rotation. Plant Physiol. 47, 756-764. doi: $10.1104 / p p .47 .6 .756$

Demontis, G. C., Aruta, C., Comitato, A., De Marzo, A., and Marigo, V. (2012). Functional and molecular characterization of rod-like cells from retinal stem cells derived from the adult ciliary epithelium. PLoS ONE 7:e33338. doi: 10.1371/annotation/ca21f359-8e8e-4c3d-8308-e0f20fc446bb

Demontis, G. C., Longoni, B., Gargini, C., and Cervetto, L. (1997). The energetic cost of photoreception in retinal rods of mammals. Arch. Ital. Biol. 135, 95-109.

Demontis, G. C., Ratto, G. M., Bisti, S., and Cervetto, L. (1995). Effect of blocking the $\mathrm{Na}+/ \mathrm{K}+$ ATPase on $\mathrm{Ca} 2+$ extrusion and light adaptation in mammalian retinal rods. Biophys. J. 69, 439-450. doi: 10.1016/S0006-3495(95) 79917-9

Di Fino, L., Casolino, M., De Santis, C., Larosa, M., La Tessa, C., Narici, L., et al. (2011). Heavy-ion anisotropy measured by ALTEA in the International Space Station. Radiat. Res. 176, 397-406. doi: 10.1667/RR2179.1

Eiraku, M., Adachi, T., and Sasai, Y. (2012). Relaxation-expansion model for self-driven retinal morphogenesis: a hypothesis from the perspective of biosystems dynamics at the multi-cellular level. Bioessays 34, 17-25. doi: 10.1002/bies.201100070

Eiraku, M., Takata, N., Ishibashi, H., Kawada, M., Sakakura, E., Okuda, S., et al. (2011). Self-organizing optic-cup morphogenesis in three-dimensional culture. Nature 472, 51-56. doi: 10.1038/nature09941

Engler, A. J., Sen, S., Sweeney, H. L., and Discher, D. E. (2006). Matrix elasticity directs stem cell lineage specification. Cell 126, 677-689. doi: $10.1016 /$ j.cell.2006.06.044
Fitzgerald, W., Chen, S., Walz, C., Zimmerberg, J., Margolis, L., and Grivel, J.-C. (2009). Immune suppression of human lymphoid tissues and cells in rotating suspension culture and onboard the International Space Station. In Vitro Cell. Dev. Biol. Anim. 45, 622-632. doi: 10.1007/s11626-009-9225-2

Fletcher, A. G., Osterfield, M., Baker, R. E., and Shvartsman, S. Y. (2014). Vertex models of epithelial morphogenesis. Biophys. J. 106, 2291-2304. doi: $10.1016 / j . b p j .2013 .11 .4498$

Gasperi, V., Rapino, C., Battista, N., Bari, M., Mastrangelo, N., Angeletti, S., et al. (2014). A functional interplay between 5-lipoxygenase and mu-calpain affects survival and cytokine profile of human Jurkat $\mathrm{T}$ lymphocyte exposed to simulated microgravity. Biomed. Res. Int. 2014:782390. doi: $10.1155 / 2014 / 782390$

Gopalakrishnan, R., Genc, K. O., Rice, A. J., Lee, S. M., Evans, H. J., Maender, C. C., et al. (2010). Muscle volume, strength, endurance, and exercise loads during 6-month missions in space. Aviat. Space Environ. Med. 81, 91-102. doi: 10.3357/ASEM.2583.2010

Grigoryan, E. N., Anton, H. J., and Mitashov, V. I. (1998). Microgravity effects on neural retina regeneration in the newt. Adv. Space Res. 22, 293-301. doi: 10.1016/S0273-1177(98)80023-9

Grigoryan, E. N., Mitashov, V. I., and Anton, H. J. (2002). Urodelean amphibians in studies on microgravity: effects upon organ and tissue regeneration. Adv. Space Res. 30, 757-764. doi: 10.1016/S0273-1177(02)00392-7

Grimm, D., Kossmehl, P., Shakibaei, M., Schulze-Tanzil, G., Pickenhahn, H., Bauer, J., et al. (2002). Effects of simulated microgravity on thyroid carcinoma cells. J. Gravit. Physiol. 9, P253-P256.

Gualandris-Parisot, L., Husson, D., Bautz, A., Durand, D., Kan, P., Aimar, C., et al. (2002). Effects of space environment on embryonic growth up to hatching of salamander eggs fertilized and developed during orbital flights. Biol. Sci. Space 16, 3-11. doi: 10.2187/bss.16.3

Hammond, T. G., and Hammond, J. M. (2001). Optimized suspension culture: the rotating-wall vessel. Am. J. Physiol. Renal Physiol. 281, F12-F25.

Hammond, T. G., Lewis, F. C., Goodwin, T. J., Linnehan, R. M., Wolf, D. A., Hire, K. P., et al. (1999). Gene expression in space. Nat. Med. 5:359. doi: 10.1038/7331

Herranz, R., Anken, R., Boonstra, J., Braun, M., Christianen, P. C., de Geest, M., et al. (2013). Ground-based facilities for simulation of microgravity: organismspecific recommendations for their use, and recommended terminology. Astrobiology 13, 1-17. doi: 10.1089/ast.2012.0876

Hoson, T., Kamisaka, S., Masuda, Y., Yamashita, M., and Buchen, B. (1997). Evaluation of the three-dimensional clinostat as a simulator of weightlessness. Planta 203(Suppl.), S187-S197. doi: 10.1007/pl00008108

Keller, R., and Shook, D. (2011). The bending of cell sheets-from folding to rolling. BMC Biol. 9:90. doi: 10.1186/1741-7007-9-90

Keyak, J. H., Koyama, A. K., LeBlanc, A., Lu, Y., and Lang, T. F. (2009). Reduction in proximal femoral strength due to long-duration spaceflight. Bone 44, 449-453. doi: 10.1016/j.bone.2008.11.014

Kwon, O., Devarakonda, S. B., Sankovic, J. M., and Banerjee, R. K. (2008). Oxygen transport and consumption by suspended cells in microgravity: a multiphase analysis. Biotechnol. Bioeng. 99, 99-107. doi: 10.1002/bit.21542

Lancaster, M. A., Renner, M., Martin, C. A., Wenzel, D., Bicknell, L. S., Hurles, M. E., et al. (2013). Cerebral organoids model human brain development and microcephaly. Nature 501, 373-379. doi: 10.1038/nature12517

Lelkes, P. I., Galvan, D. L., Hayman, G. T., Goodwin, T. J., Chatman, D. Y., Cherian, S., et al. (1998). Simulated microgravity conditions enhance differentiation of cultured PC12 cells towards the neuroendocrine phenotype. In Vitro Cell. Dev. Biol. Anim. 34, 316-325. doi: 10.1007/s11626-998-0008-y

Lü, D., Luo, C., Zhang, C., Li, Z., and Long, M. (2014). Differential regulation of morphology and stemness of mouse embryonic stem cells by substrate stiffness and topography. Biomaterials 35, 3945-3955. doi: 10.1016/j.biomaterials.2014.01.066

Ma, X., Pietsch, J., Wehland, M., Schulz, H., Saar, K., Hübner, N., et al. (2014). Differential gene expression profile and altered cytokine secretion of thyroid cancer cells in space. FASEB J. 28, 813-835. doi: 10.1096/fj.13243287

Mueller-Klieser, W., Freyer, J. P., and Sutherland, R. M. (1986). Influence of glucose and oxygen supply conditions on the oxygenation of multicellular spheroids. Br. J. Cancer 53, 345-353. doi: 10.1038/bjc.1986.58

Nakagawa, M., Koyanagi, M., Tanabe, K., Takahashi, K., Ichisaka, T., Aoi, T., et al. (2008). Generation of induced pluripotent stem cells without Myc from 
mouse and human fibroblasts. Nat. Biotechnol. 26, 101-106. doi: 10.1038/ nbt1374

Nakano, T., Ando, S., Takata, N., Kawada, M., Muguruma, K., Sekiguchi, K., et al. (2012). Self-formation of optic cups and storable stratified neural retina from human ESCs. Cell Stem Cell 10, 771-785. doi: 10.1016/j.stem.2012.05.009

Neff, A. W., Yokota, H., Chung, H. M., Wakahara, M., and Malacinski, G. M. (1993). Early amphibian (anuran) morphogenesis is sensitive to novel gravitational fields. Dev. Biol. 155, 270-274. doi: 10.1006/dbio.1993. 1024

Nelson, E. S., Mulugeta, L., and Myers, J. G. (2014). Microgravity-induced fluid shift and ophthalmic changes. Life 4, 621-665. doi: 10.3390/life4040621

Pearson, J. (2004). The effects of simulated microgravity on avian embryonic development. Biol. Sci. Space 18, 122-123.

Pietsch, J., Ma, X., Wehland, M., Aleshcheva, G., Schwarzwälder, A., Segerer, J., et al. (2013). Spheroid formation of human thyroid cancer cells in an automated culturing system during the Shenzhou-8 Space mission. Biomaterials 34, 7694-7705. doi: 10.1016/j.biomaterials.2013.06.054

Pinsky, L. S., Osborne, W. Z., Hoffman, R. A., and Bailey, J. V. (1975). Light flashes observed by astronauts on Skylab 4. Science 188, 928-930. doi: $10.1126 /$ science.188.4191.928

Plett, P. A., Abonour, R., Frankovitz, S. M., and Orschell, C. M. (2004). Impact of modeled microgravity on migration, differentiation, and cell cycle control of primitive human hematopoietic progenitor cells. Exp. Hematol. 32, 773-781. doi: 10.1016/j.exphem.2004.03.014

Ruiz, S. A., and Chen, C. S. (2008). Emergence of patterned stem cell differentiation within multicellular structures. Stem Cells 26, 2921-2927. doi: 10.1634/stemcells.2008-0432

Sambandam, Y., Townsend, M. T., Pierce, J. J., Lipman, C. M., Haque, A., Bateman, T. A., et al. (2014). Microgravity control of autophagy modulates osteoclastogenesis. Bone 61, 125-131. doi: 10.1016/j.bone.2014.01.004

Sasai, Y., Eiraku, M., and Suga, H. (2012). In vitro organogenesis in three dimensions: self-organising stem cells. Development 139, 4111-4121. doi: 10.1242/dev.079590

Sekulic, S. R., Lukac, D. D., and Naumovic, N. M. (2005). The fetus cannot exercise like an astronaut: gravity loading is necessary for the physiological development during second half of pregnancy. Med. Hypotheses 64, 221-228. doi: 10.1016/j.mehy.2004.08.012

Shimada, N., Sokunbi, G., and Moorman, S. J. (2005). Changes in gravitational force affect gene expression in developing organ systems at different developmental times. BMC Dev. Biol. 5:10. doi: 10.1186/1471-213X-5-10

Souza, K. A., Black, S. D., and Wassersug, R. J. (1995). Amphibian development in the virtual absence of gravity. Proc. Natl. Acad. Sci. U.S.A. 92, 1975-1978. doi: 10.1073/pnas.92.6.1975

Suda, T. (1998). Lessons from the space experiment SL-J/FMPT/L7: the effect of microgravity on chicken embryogenesis and bone formation. Bone 22, 73S-78S. doi: 10.1016/s8756-3282(98)00021-0

Sutherland, R. M., Sordat, B., Bamat, J., Gabbert, H., Bourrat, B., and MuellerKlieser, W. (1986). Oxygenation and differentiation in multicellular spheroids of human colon carcinoma. Cancer Res. 46, 5320-5329.

Taibbi, G., Cromwell, R. L., Kapoor, K. G., Godley, B. F., and Vizzeri, G. (2013). The effect of microgravity on ocular structures and visual function: a review. Surv. Ophthalmol. 58, 155-163. doi: 10.1016/j.survophthal.2012.04.002

Takahashi, K., Tanabe, K., Ohnuki, M., Narita, M., Ichisaka, T., Tomoda, K., et al. (2007). Induction of pluripotent stem cells from adult human fibroblasts by defined factors. Cell 131, 861-872. doi: 10.1016/j.cell.2007.11.019

Ulbrich, C., Wehland, M., Pietsch, J., Aleshcheva, G., Wise, P., van Loon, J., et al. (2014). The impact of simulated and real microgravity on bone cells and mesenchymal stem cells. Biomed Res. Int. 2014:928507. doi: $10.1155 / 2014 / 928507$
Underwood, M. A., Gilbert, W. M., and Sherman, M. P. (2005). Amniotic fluid: not just fetal urine anymore. J. Perinatol. 25, 341-348. doi: 10.1038/sj.jp.7211290

Valles, J. M. Jr., and Guevorkian, K. (2002). Low gravity on earth by magnetic levitation of biological material. J. Gravit. Physiol. 9, P11-P14.

Versari, S., Longinotti, G., Barenghi, L., Maier, J. A., and Bradamante, S. (2013). The challenging environment on board the International Space Station affects endothelial cell function by triggering oxidative stress through thioredoxin interacting protein overexpression: the ESA-SPHINX experiment. FASEB J. 27, 4466-4475. doi: 10.1096/fj.13-229195

Wakayama, S., Kawahara, Y., Li, C., Yamagata, K., Yuge, L., and Wakayama, T. (2009). Detrimental effects of microgravity on mouse preimplantation development in vitro. PLOS ONE 4:e6753. doi: 10.1371/journal.pone.0 006753

Wang, Y., An, L., Jiang, Y., and Hang, H. (2011). Effects of simulated microgravity on embryonic stem cells. PLoS ONE 6:e29214. doi: 10.1371/journal.pone.0029214

Warnke, E., Pietsch, J., Wehland, M., Bauer, J., Infanger, M., Görög, M., et al. (2014). Spheroid formation of human thyroid cancer cells under simulated microgravity: a possible role of CTGF and CAV1. Cell Commun. Signal. 12:32. doi: 10.1186/1478-811X-12-32

Weststrate, J. A., and Deurenberg, P. (1989). Body composition in children: proposal for a method for calculating body fat percentage from total body density or skinfold-thickness measurements. Am. J. Clin. Nutr. 50, 1104-1115.

Xie, Y., Wang, F., Zhong, W., Puscheck, E., Shen, H., and Rappolee, D. A. (2006). Shear stress induces preimplantation embryo death that is delayed by the zona pellucida and associated with stress-activated protein kinase-mediated apoptosis. Biol. Reprod. 75, 45-55. doi: 10.1095/biolreprod.105.049791

Yan, M., Wang, Y., Yang, M., Liu, Y., Qu, B., Ye, Z., et al. (2015). The effects and mechanisms of clinorotation on proliferation and differentiation in bone marrow mesenchymal stem cells. Biochem. Biophys. Res. Commun. 460, 327-332. doi: 10.1016/j.bbrc.2015.03.034

Ye, X., Wang, Y., and Nathans, J. (2010). The Norrin/Frizzled4 signaling pathway in retinal vascular development and disease. Trends Mol. Med. 16, 417-425. doi: 10.1016/j.molmed.2010.07.003

Yuge, L., Kajiume, T., Tahara, H., Kawahara, Y., Umeda, C., Yoshimoto, R., et al. (2006). Microgravity potentiates stem cell proliferation while sustaining the capability of differentiation. Stem Cells Dev. 15, 921-929. doi: $10.1089 / \mathrm{scd} .2006 .15 .921$

Zarbin, M. (2016). Cell-based therapy for degenerative retinal disease. Trends Mol. Med. 22, 115-134. doi: 10.1016/j.molmed.2015.12.007

Zarbin, M. A., Casaroli-Marano, R. P., and Rosenfeld, P. J. (2014). Agerelated macular degeneration: clinical findings, histopathology and imaging techniques. Dev. Ophthalmol. 53, 1-32. doi: 10.1159/000358536

Zhong, X., Gutierrez, C., Xue, T., Hampton, C., Vergara, M. N., Cao, L. H., et al. (2014). Generation of three-dimensional retinal tissue with functional photoreceptors from human iPSCs. Nat. Commun. 5:4047. doi: $10.1038 /$ ncomms5047

Conflict of Interest Statement: The authors declare that the research was conducted in the absence of any commercial or financial relationships that could be construed as a potential conflict of interest.

Copyright (c) 2017 Andreazzoli, Angeloni, Broccoli and Demontis. This is an openaccess article distributed under the terms of the Creative Commons Attribution License (CC BY). The use, distribution or reproduction in other forums is permitted, provided the original author(s) or licensor are credited and that the original publication in this journal is cited, in accordance with accepted academic practice. No use, distribution or reproduction is permitted which does not comply with these terms. 